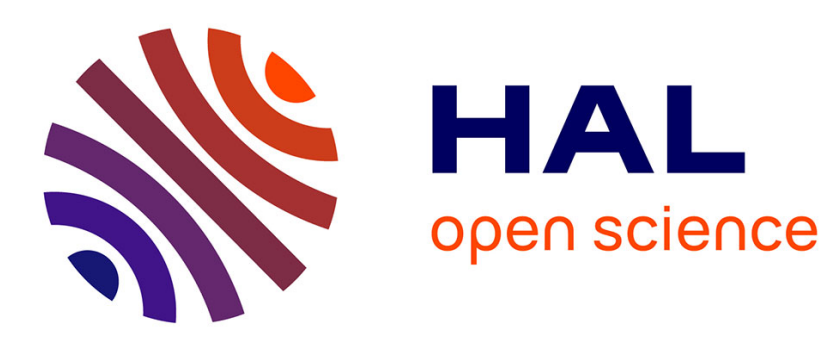

\title{
Jahn-Teller Effect in Copper-Doped Spinel Group
}

V. Shapovalov, H. Szymczak, S. Piechota

\section{To cite this version:}

V. Shapovalov, H. Szymczak, S. Piechota. Jahn-Teller Effect in Copper-Doped Spinel Group. Journal de Physique IV Proceedings, 1997, 07 (C1), pp.C1-243-C1-244. 10.1051/jp4:1997193 . jpa-00255140

\section{HAL Id: jpa-00255140 https://hal.science/jpa-00255140}

Submitted on 1 Jan 1997

HAL is a multi-disciplinary open access archive for the deposit and dissemination of scientific research documents, whether they are published or not. The documents may come from teaching and research institutions in France or abroad, or from public or private research centers.
L'archive ouverte pluridisciplinaire HAL, est destinée au dépôt et à la diffusion de documents scientifiques de niveau recherche, publiés ou non, émanant des établissements d'enseignement et de recherche français ou étrangers, des laboratoires publics ou privés. 


\title{
Jahn-Teller Effect in Copper-Doped Spinel Group
}

\author{
V.A. Shapovalov, H. Szymczak*, S. Piechota* and V.V. Shapovalov** \\ Donetsk Physico-Technical Institute, Academy of Sciences of Ukraine, R. Luxemburg 72, \\ 340114 Donetsk, Ukraine \\ * Institute of Physics, Polish Academy of Sciences, Al. Lotnikow 32, 02-668 Warszawa, Poland \\ ** Department of Physics, Queens College of the City, University of New York, New York, NY 11367, \\ U.S.A.
}

\begin{abstract}
Anomalous magnetic properties and various phase transitions observed in some spinels are due to the Jahn-Teller effect. The effect is rather effectively studied in corresponding diamagnetic analogues of such crystals.In the present paper a group of single crystals of normal and converted spinels doped with the two-valent copper $\mathrm{Cu}^{2+}$ has been investigated. In this group of spinels the effect of inversion splitting shows itself classically. The investigations have been done by using radiospectrometers of 10 and $37 \mathrm{GHz}$ frequency in the temperature tange 4-300 K.For the first time, in the low-frequency range at the frequency of $10 \mathrm{GHz}$ the full complex of the EPR spectra have been registered which are due to the theory of the inversion splitting.It consists of five types of the EPR spectra which are due to allowed $3^{-}-3^{+}, 2^{-}-2^{+}, 1^{-}-1^{+}$and forbidden $3^{-}-1^{+}, 1^{+}-2^{-}$ transitions. At passing to a higher frequency of $37 \mathrm{GHz}$ there occurs the frequency transformation of the spectrum, the two EPR spectra are observed which have been observed by many authors in copper complexes in the case of Jahn-Teller effect developing.
\end{abstract}

\section{INTRODUCTION}

At present have been developed the general situation of the model of the Jahn-Teller effect.A large quantity of the experiment works has been perfomed. But it is not clear in the explanation and understanding of the appearance of the Jahn-Teller effect in the EPR spectra.It is necessary to find such an object of the investigations in which the Jahn-Teller effect appears in full. In this paper we study the octahedral copper complex. The ion $\mathrm{Cu}^{2+}$ is situated in the oxygen octahedron. The ground state of the $\mathrm{Cu}^{2+}$ ion $\left(3 \mathrm{~d}^{9}\right)$ in an octahedral field has a low-lying orbital doublet $E$. The low-lying level is orbital singlet which has the $\left|\mathrm{x}^{2}-\mathrm{y}^{2}\right\rangle$ wave function. The Jahn-Teller effect is maximum for the D-ions. And such $\mathrm{dg}$-electrons make the large Jahn-Teller distortions. Therefore we have the maximum effect for the $\mathrm{Cu}^{2+}$-complexs $\left(3 \mathrm{~d}^{9}\right)$. And the posibility of the appearance of the Jahn-Teller effect depends on the value of the inner asymmetry of the complex. The phenomenon of the inner asymmetry can take place in the case of the nonequivalent replacement. For example this is the case of replacement of the ion $\mathrm{Li}^{+}$by the ion $\mathrm{Cu}^{2+}$ in $\mathrm{LiGa}_{5} \mathrm{O}_{8}$. In the spinel a ion $\mathrm{Cu}^{2+}$ is compeled to displace from the center of the cation node. Such position of the $\mathrm{Cu}^{2+}$ has provided a clear appearance of Jahn-Teller effect [1] in Li-spinels. In other matrices for example $\mathrm{ZnAl}_{2} \mathrm{O}_{4}$ and $\mathrm{MgAl}_{2} \mathrm{O}_{4}$ the appearance of the Jahn-Teller effect is very small. Because the $\mathrm{Cu}^{2+}$-ions have replaced $\mathrm{Zn}^{2+}-$ and $\mathrm{Mg}^{2+}-$ ions. They are central symmetrical.

\section{RESULTS AND DISCUSSION}

The investigations of copper $\mathrm{Jahn}-\mathrm{Teller}$ complexes in the single crystals of $\mathrm{LiGa}_{5} \mathrm{O}_{8}, \mathrm{LiAl}_{5} \mathrm{O}_{8}$ inversion and $\mathrm{ZnAl} \mathrm{O}_{4}$, $\mathrm{MgAl}_{2} \mathrm{O}_{4}, \mathrm{ZnGa}_{2} \mathrm{O}_{4}, \mathrm{MgGa}_{2} \mathrm{O}_{4}$ normal spinels at the 10 and $37 \mathrm{GHz}$ and in the region of the temperatures $\mathrm{T}=4-300 \mathrm{~K}$ have been performed. The results of the investigation are given for the $\mathrm{LiGa}_{5} \mathrm{O}_{8}$. Because there are most full and allowed EPR spectra in this matrix. If we take not into account the inversion splitting,we shall observe the single line without the frequency and temperature dependence. If we do not take into account the inversion splitting, we shall observe a very complicated EPR spectrum. Such spectrum must have the characteristic frequency and temperature depedence. In the case $S=1 / 2$ we shall have the three doublets and six levels in the magnetic field. We had to observe the five transitions in the low frequency region 1 [1]. There are three allowed transitions which correspond to the allowed $3^{-}-3^{+}, 2^{-}-2^{+}, 1^{-}-1^{+}$and two forbidden $3^{-}-1^{+}, 1^{+}-2^{-}$ transitions. This case corresponds to microwave frequency $10 \mathrm{GHz}$. Spectrum must contain one line for each from three potential minima corresponding to a distortion of the complex along one of the cubic axes. The intensity of these lines 
decreases with the increase of temperature. There appears an isotropic line. The investigations of the EPR spectra of the ions $\mathrm{Cu}^{2+}$ in $\mathrm{LiGa}_{5} \mathrm{O}_{8}$ at frequency $37 \mathrm{GHz}$ at $\mathrm{T}=4-300 \mathrm{~K}$ have showen the presence of axial and isotropic spectrum which corresponds to intermediate region 2[1]. The axial spectrum is the static spectrum of the Jahn-Teller effect. We have found the following spin Hamiltonian parameters: $\mathrm{g}_{\|}=2,386 \pm 0,002 ; \mathrm{A}=111 \pm 2 \mathrm{Oe} ; \mathrm{g}_{\perp}=2,082 \pm 0,003 ; \mathrm{B}=0$. The spectrum is in the temperature region $T=4-200 \mathrm{~K}$. The hyperfine structure of the spectrum is at $\mathrm{T}=4-150 \mathrm{~K}$. The isotropic spectrum is the dynamic spectrum of the Jahn-Teller effect.The temperature region of the existence of the spectrum is $T=30-300 \mathrm{~K}$, $\mathrm{g}=2,176 \pm 0,007$. The maximum intensity of this isotropic spectrum is observed at $\mathrm{T}=110 \mathrm{~K}$. The investigation of the EPR spectra of the ions $\mathrm{Cu}^{2+}$ in $\mathrm{LiGa}_{5} \mathrm{O}_{8}$ at $\mathrm{T}=4-300 \mathrm{~K}$ at frequency $10 \mathrm{GHz}$ allowed to observe the whole complex of lines which correspond to the transitions which are described in the inversion splitting theory by I.B.Bersuker. The three observed spectra (1, 2 and 3) correspond to above-mentioned allowed transitions. The two observed spectra 4 and 5 correspond to forbidden transitions. The two spectra 1 and 2 can be described by an axial spin Hamiltonian with $S=1 / 2$ and $I=3 / 2$. It has the following spin Hamiltonian parameters: $g_{\|}=2,379 \pm 0,002 ; \mathrm{A}=90 \pm 2 \mathrm{Oe} ; \mathrm{g}_{\perp}=2,074 \pm 0,003 ; \mathrm{B}=26 \pm 2$ Oe. The parallel orientation of the spectra coincides with $a<100>$ direction. The spectrum 1 at the $T=8,5 \mathrm{~K}$ is very good allowed in parallel (lines $1-4)$ and perpendicular (lines 5-8) orientations. The other lines at the $T=8,5 \mathrm{~K}$ are not observed. The spectrum 1 describes the an octahedron distorted along one of the three four-fold axes by the Jahn-Teller effect at low temperature. It characterizes the static Jahn-Teller effect. Therefore it is called the static $(S)$ spectrum. Its intensity decreases when temperature increases. The spectrum 2 appears when the intensity of the spectrum 1 starts decreasing. The spectrum 2 correspond to $3^{--} 3^{+}$transition of the excited intermediate doublet of the ground state ion $\mathrm{Cu}^{2+}[1]$. The intensity of the spectrum 2 , by comparison with the intensity of the spectrum 1, increases with the increase of temperature. Therefore it is called the dynamic (D1) spectrum. At $\mathrm{T}=18 \mathrm{~K}$ the spectrum D1 is very good allowed in parallel (lines 9-12) and perpendicular (lines 13-16) orientations. It has the following spin Hamiltonian parameters: $\mathrm{g}_{\mid:}=2,343 \pm 0,002 ; \mathrm{A}=85 \pm 2 \mathrm{Oe} ; \mathrm{g}_{\perp}=2,018 \pm 0,002 ; \mathrm{B}=55 \pm 2$ Oe. The spectrum 3 appear at $\mathrm{T}=36 \mathrm{~K}$.It is isotropic and correspond to $2^{-}-2^{+}$transition of the upper doublet of the ground state ion $\mathrm{Cu}^{2+}$. The intensity of the spectrum D2, by comparison with the intensity of the spectrum 1 , increases with the increase of the temperature. Therefore it is called the dynamic (D2) spectrum. The spin Hamilionian parameters of the spectrum 3: $\mathrm{g}=2,138 \pm 0,003 ; \mathrm{A}=55 \pm 2 \mathrm{Oe}$. The growth of relative intensities of the dynamic spectra D1 and D2 at the increase of temperature corresponds to the increase of Bolzman population of the excited intermediate and upper doublet states. The upper doublet is separated from the ground state by slot and has isotropic EPR spectrum. The forbidden spectra 4 and 5 (F) are observed in parallel orientation.In paper [2] it is reported about of possibility of the clear observation of such transitions with the magnetic field along $a<111>$ direction. We observed such transitions. The intensity of the F-spectra, by comparison with the intensity of the ground spectra, increases with the increase of temperature.

\section{CONCLUSSIONS}

We have succeeded in the observation of the whole complex of spectra which corresponds to the theory of the inversion splitting at the lowfrequency $10 \mathrm{GHz}$ and at the high frequency $37 \mathrm{GHz}$. The roul of the mechanism of dynamic narrowing of the resonance lines and of the mechanism connected with population of the excited states in the formation of the EPR spectrum and its temperature and frequency transformations is analysed.

\section{Acknowledgments}

The authors are grateful to M.Zaripov (KFTI RAN Kazan Russia) for useful discussions.

\section{References}

[1] Shapovalov V., Szymczak H., Piechota C., Borowiec M. Jahn-Teller effect in LiGa $5 \mathrm{O}_{8}$ spinel. Molec.Phys.Rep. 5 (1994) 256-260.

[2] Bersuker I.B. Spin inversion levels in a magnetic field and the EPR spectrum of octahedral Cu${ }^{2+}$ ion complexes. Zh.Exp.Theor.Phys. 44 (1963) 1239-1247 (in Russian). 